\title{
Inappropriately low plasma leptin concentration in the cachexia associated with chronic heart failure
}

\author{
D R Murdoch, E Rooney, H J Dargie, D Shapiro, J J Morton, J J V McMurray
}

\begin{abstract}
Background-Cardiac cachexia is a syndrome of generalised wasting which caries a poor prognosis and is associated with raised plasma concentrations of tumour necrosis factor $\alpha$ (TNF $\alpha)$. TNF $\alpha$ increases secretion of leptin, a hormone which decreases food intake and increases energy expenditure.
\end{abstract}

Objective-To determine whether an inappropriate increase in plasma leptin concentration contributes to the cachexia of chronic heart failure.

Design-Retrospective case-control study. Setting-Tertiary referral cardiology unit. Patients-110 human subjects comprising 29 cachectic chronic heart failure patients, 22 non-cachectic chronic heart failure patients, 33 patients with ischaemic heart disease but normal ventricular function, and 26 healthy controls.

Interventions-Measurement of: body fat content by skinfold thickness (cachectic males $<27 \%$, females $<29 \%$ ); plasma leptin, TNF $\alpha$, and noradrenaline (norepinephrine); central haemodynamics in chronic heart failure patients at right heart catheterisation.

Main outcome measures-Plasma leptin concentration corrected for body fat content, plasma TNF $\alpha$ and noradrenaline concentration, and central haemodynamics.

Results-Mean (SEM) plasma leptin concentrations were: $6.2(0.6) \mathrm{ng} / \mathrm{ml}$ (cachectic heart failure), 16.9 (3.6) $\mathrm{ng} / \mathrm{ml}$ (noncachectic heart failure), $16.8(3.0) \mathrm{ng} / \mathrm{ml}$ (ischaemic heart disease), and 18.3 (3.5) $\mathrm{ng} / \mathrm{ml}$ (control) ( $\mathrm{p}<0.001$ for cachectic heart failure $v$ all other groups). Plasma leptin concentration remained significantly lower in the cachectic heart failure group even after correcting for body fat content and in spite of significantly increased TNF $\alpha$ concentrations. Thus plasma leptin was inappropriately low in cachectic chronic heart failure in the face of a recognised stimulus to its secretion. There was no significant correlation between plasma leptin, New York Heart Association class, ejection fraction, or any haemodynamic indices.

Conclusions-Leptin does not contribute to the cachexia of chronic heart failure. One or more leptin suppressing mechanisms may operate in this syndrome-for example, the sympathetic nervous system. (Heart 1999;82:352-356)

Keywords: heart failure; cytokines; leptin; cachexia
Leptin, the recently identified product of the obesity (ob) gene, is a 167 amino acid hormone that is produced by adipose tissue. ${ }^{12}$ Leptin acts within the brain to decrease food intake, especially fat intake, and increase thermogenesis, probably by inhibiting the synthesis and release of hypothalamic neuropeptide $\mathrm{Y}^{3}$

Dysfunction of this negative feedback loop has been suggested as a mechanism underlying disorders involving abnormalities in body fat content such as obesity, where relative underproduction of leptin has been postulated. ${ }^{24-6} \mathrm{It}$ is also possible that alterations in the synthesis or release of leptin, leading to its overproduction, may underlie the cachexia that often accompanies chronic medical conditions-for example chronic heart failure, which is characterised by selective loss of adipose tissue. We and others have reported that cachexia in chronic heart failure is associated with increased plasma concentrations of tumour necrosis factor $\alpha(\mathrm{TNF} \alpha)$ and other cytokines. $^{7-9}$ TNF $\alpha$ and interleukin-1 have been reported to increase plasma leptin concentrations in a dose dependent fashion in several species including humans. ${ }^{10-12}$ Increased plasma leptin concentrations might therefore contribute to cachexia in patients with chronic heart failure, as has been suggested in other wasting conditions such as cancer. ${ }^{13}$ The present study was designed to test this hypothesis.

\section{Methods}

This investigation conforms to the principles outlined in the declaration of Helsinki and was approved by the local committee on medical ethics. All patients gave written informed consent.

\section{PATIENTS}

\section{Chronic heart failure}

We studied 51 patients (nine female, 42 male), aged 52 to 83 years (mean 66.1), with stable chronic heart failure of more than three months' duration. All patients had a left ventricular ejection fraction of $\leqslant 35 \%$, measured by radionuclide ventriculography. None had significant concomitant disease, especially infection, renal or hepatic dysfunction (defined as creatinine $>250 \mu \mathrm{mol} / 1$ or transaminase values more than three times the upper limit of normal, respectively), malignancy, chronic lung disease, thyroid disease, or connective tissue disease. The primary cause of heart failure was coronary artery disease in 48 patients and regurgitant valve disease in three. Twenty five patients were in New York Heart Association (NYHA) class II, 23 in class III, and three in class IV.

\author{
Accepted for publication \\ 18 March 1999 \\ Correspondence to: \\ Dr Murdoch.
}


Ischaemic heart disease

To exclude an independent effect of ischaemic heart disease on plasma leptin concentration, we studied 33 matched patients (eight female, 25 male), aged 39 to 76 years (mean 59.2), with ischaemic heart disease but normal left ventricular function. All these patients had angiographic evidence of obstructive coronary disease but a normal contrast ventriculogram, and they had reversible myocardial ischaemia on exercise ECG testing or thallium myocardial perfusion imaging.

\section{Normal volunteers}

We also studied 26 matched healthy volunteers (16 female, 10 male), aged 30 to 76 years (mean 60.1). None had a history of chronic illness or was taking regular drug treatment. All had a normal transthoracic echocardiogram, maximum symptom limited exercise ECG test, and pulmonary function tests.

BODY FAT ESTIMATION

A single practised observer measured biceps, triceps, infrascapular, and suprailiac skinfold thickness, in triplicate, by the method of Durnin and Womersley, as previously described. ${ }^{14}$ The percentage body fat content was derived from the sum of the mean of these measurements according to standard tables. ${ }^{15}$ Patients were defined as cachectic (males with body fat $<27 \%$, females $<29 \%$ ) or noncachectic on the basis of percentage body fat content. This definition is based on previously published data on our local population, ${ }^{15}$ and has been used in a previous study from our group. ${ }^{7}$

Body mass index (BMI) was also calculated in the usual way (weight $(\mathrm{kg})$ divided by square of the height $\left.\left(\mathrm{m}^{2}\right)\right)$.

\section{SAMPLE COLLECTION AND PEPTIDE ASSAY \\ Blood collection}

Ten millilitres of blood were drawn from an antecubital vein, following an overnight fast and after at least 30 minutes' supine rest, into chilled tubes containing potassium EDTA (1 $\mathrm{mg} / \mathrm{ml}$ blood $)$ and aprotinin $(50 \mathrm{KIU} / \mathrm{ml}$ blood). Samples were immediately centrifuged at $4^{\circ} \mathrm{C}$ and the separated plasma stored at $-20^{\circ} \mathrm{C}$ until assay. All samples were assayed in a single batch within six months of collection in a blinded fashion. Plasma leptin, $\mathrm{TNF} \alpha$, and noradrenaline (norepinephrine) were measured in the same plasma samples.

Plasma leptin measurement

Plasma leptin ( $\mathrm{ng} / \mathrm{ml}$ ) was assayed, without previous extraction of plasma, using a commercially available direct, specific, monoclonal antibody radioimmunoassay kit supplied by Linco Research Inc (St Charles, Minnesota, USA). The within assay and between assay coefficients of variation are $3.4 \%$ to $8.3 \%$ and $3.0 \%$ to $6.2 \%$, respectively. All assays were run in duplicate and the average of the two measurements reported.

Plasma TNFa measurement

Plasma TNF $\alpha(\mathrm{pg} / \mathrm{ml})$ was assayed using a commercially available solid phase enzyme amplified sensitivity immunoassay (EASIA) kit supplied by BioSource Europe SA (Fleurus, Brussels, Belgium). The within assay and between assay coefficients of variation are 3.7\% to $5.2 \%$ and $8.0 \%$ to $9.9 \%$, respectively. The minimum detectable concentration and approximate normal range for this assay in healthy subjects are $3 \mathrm{pg} / \mathrm{ml}$ and 0 to $20 \mathrm{pg} / \mathrm{ml}$, respectively. All assays were run in duplicate and the average of the two measurements reported.

Plasma noradrenaline measurement

Plasma noradrenaline (nmol/l) was extracted from plasma and assayed by high performance liquid chromatography and electrochemical detection as previously described. ${ }^{16}$ The within assay and between assay coefficients of variation are both $<10 \%$ and the approximate normal range for this assay in healthy volunteers is $<5.0 \mathrm{nmol} / \mathrm{l}$.

HAEMODYNAMIC MEASUREMENTS

Forty two of the patients with heart failure were admitted to hospital as day cases for assessment of central haemodynamic variables by right heart catheterisation. A balloon tipped pulmonary thermodilution catheter was inserted through the femoral vein and advanced to an appropriate position within the pulmonary artery. Following a period of stabilisation of at least one hour, measurements of systemic arterial pressure, right atrial pressure, mean pulmonary artery pressure, and pulmonary capillary wedge pressure were made. Cardiac output was also measured by the thermodilution method and systemic vascular resistance was derived in the usual fashion. An average of at least three of each measurements were taken (five for cardiac output) and the mean recorded.

\section{STATISTICAL ANALYSIS}

All values are expressed as mean (SEM). Two sample $t$ tests, linear regression analysis, and analysis of covariance were used as appropriate. The two analyses of primary interest (comparison of serum leptin and $\mathrm{TNF} \alpha$ between cachectic and non-cachectic chronic heart failure patients) were taken at face value; otherwise the Bonferroni correction was applied to all other analyses to control for multiple comparisons. ${ }^{17}$ To allow for comparison between groups, plasma leptin concentration was corrected according to per cent body fatthat is, corrected plasma leptin = plasma leptin concentration (ng/ml) / \%body fat. A probability (p) value of $<0.05$ was considered significant.

\section{Results}

PERCENTAGE BODY FAT AND BODY MASS INDEX Of 51 patients with chronic heart failure, 29 were defined as cachectic according to skinfold measurement derived estimates of percentage body fat. The mean (SEM) body fat content of these patients was $22.2(1.0) \%$, compared with $31.0(0.65) \%$ in the 22 non-cachectic patients. By comparison, BMI was $22.6(0.61) \mathrm{kg} / \mathrm{m}^{2}$ and $29.0(0.59) \mathrm{kg} / \mathrm{m}^{2}$ in these two groups, 
Table 1 Results of measured variables in the four groups

\begin{tabular}{lllll}
\hline & Normal & IHD & Non-cachectic CHF & Cachectic CHF \\
\hline Age (years) & $60.1(2.0)$ & $59.2(1.7)$ & $63.4(1.4)$ & $68.2(1.5)$ \\
Body fat (\%) & $31.5(1.4)$ & $28.0(0.9)$ & $31.0(0.7)$ & $22.2(1.0)$ \\
Body mass index $\left(\mathrm{kg} / \mathrm{m}^{2}\right)$ & $28.6(1.0)$ & $27.2(0.6)$ & $29.0(0.6)$ & $22.6(0.6)$ \\
Leptin $(\mathrm{ng} / \mathrm{ml})$ & $18.3(3.5)$ & $16.8(3.0)$ & $16.9(3.6)$ & $6.2(0.6)^{\star}+\ddagger$ \\
TNF $(\mathrm{pg} / \mathrm{ml})$ & - & $22.7(1.7)$ & $21.6(1.8)$ & $30.5(2.7) \S$ \\
Noradrenaline (nmol/1) & - & - & $3.5(0.3)$ & $4.5(0.4)$
\end{tabular}

Values are mean (SEM)

${ }^{\star} \mathrm{p}<0.001$ ( $v$ normal); $\mathrm{tp}<0.001$ ( $v$ non-cachectic); $\neq \mathrm{p}<0.001$ ( $v$ IHD); $\mathrm{p}=0.006(v$ non-cachectic); $\uparrow \mathrm{p}<0.05$ ( $v$ IHD), corrected for multiple comparisons.

$\mathrm{CHF}$, chronic heart failure; IHD, ischaemic heart disease; TNF, tumour necrosis factor.

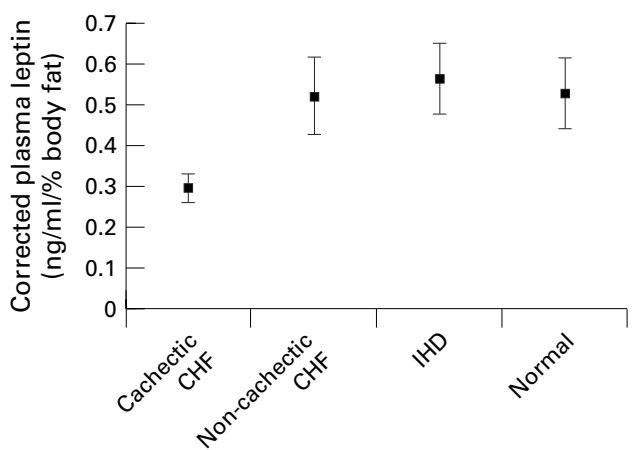

Patient group

Figure 1 Corrected plasma leptin concentration ( $\mathrm{ng} / \mathrm{ml} /$ $\%$ body fat) according to patient group. Error bars indicate SEM. CHF, chronic heart failure; IHD, ischaemic heart disease.

respectively. Mean values for percentage body fat in patients with ischaemic heart disease and in healthy volunteers were $28.0(0.9) \%$ and 31.5 (1.4)\%, respectively; mean BMI values were $27.2(0.6) \mathrm{kg} / \mathrm{m}^{2}$ and $28.6(0.95) \mathrm{kg} / \mathrm{m}^{2}$, respectively (table 1 ).

PLASMA LEPTIN CONCENTRATIONS

The mean plasma leptin concentration was 6.2 (0.6) $\mathrm{ng} / \mathrm{ml}$ in cachectic chronic heart failure patients, 16.9 (3.6) $\mathrm{ng} / \mathrm{ml}$ in non-cachectic chronic heart failure patients, 16.8 (3.0) ng/ml in ischaemic heart disease patients, and 18.3 (3.5) $\mathrm{ng} / \mathrm{ml}$ in healthy volunteers. Plasma leptin was significantly lower in the cachectic heart failure patients than in non-cachectic heart failure patients, ischaemic heart disease patients, or healthy volunteers ( $p<0.001$ for all). There was no significant difference in plasma leptin concentration between the other groups (table 1).

After correction for body fat content, plasma leptin concentration remained significantly lower in cachectic heart failure patients $(0.296$ (0.035) $\mathrm{ng} / \mathrm{ml} / \%$ body fat) than in noncachectic heart failure patients $(0.521$ (0.095); $\mathrm{p}=0.03)$, ischaemic heart disease patients (0.563 (0.087); p < 0.01), or healthy volunteers $(0.529$ (0.086); $\mathrm{p}=0.02$ ) (fig 1). Plasma leptin concentration was thus found to be inappropriately low in cachectic chronic heart failure - that is, lower than could be accounted for by differences in body fat content.

PLASMA TNF $\alpha$ CONCENTRATIONS

The mean plasma $\mathrm{TNF} \alpha$ concentration was 30.5 (2.7) $\mathrm{pg} / \mathrm{ml}$ in cachectic heart failure patients, $21.6(1.8) \mathrm{pg} / \mathrm{ml}$ in non-cachectic heart failure patients, and $22.7(1.7) \mathrm{pg} / \mathrm{ml}$ in

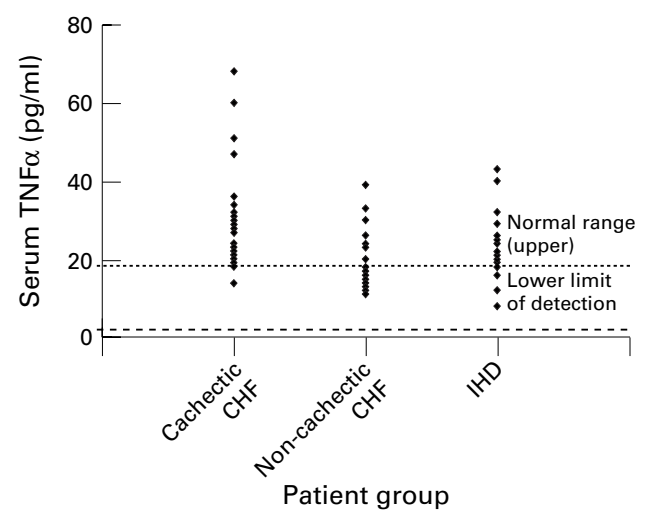

Figure 2 Distribution of plasma tumour necrosis factor $a$ (TNFa) (pg/ml) according to patient group. CHF, chronic heart failure; IHD, ischaemic heart disease.

Table 2 Comparison of haemodynamics in patients with cachectic and non-cachectic chronic heart failure (CHF)

\begin{tabular}{|c|c|c|}
\hline & Non-cachectic & Cachectic \\
\hline NYHA class & $2.4(0.1)$ & $2.7(0.1)^{\star}$ \\
\hline Ejection fraction (\%) & $24.4(1.9)$ & $23.9(1.9)$ \\
\hline Right atrial pressure $(\mathrm{mm} \mathrm{Hg})$ & $4.6(0.5)$ & $4.8(0.6)$ \\
\hline $\begin{array}{l}\text { Mean pulmonary artery pressure } \\
(\mathrm{mm} \mathrm{Hg})\end{array}$ & $17.8(1.0)$ & $18.9(1.8)$ \\
\hline $\begin{array}{l}\text { Systemic vascular resistance } \\
\left(\text { dynes } / \mathrm{cm}^{3}\right)\end{array}$ & $1788(99.5)$ & $1887(84.2)$ \\
\hline $\begin{array}{l}\text { Pulmonary artery wedge pressure } \\
(\mathrm{mm} \mathrm{Hg})\end{array}$ & $11.9(0.9)$ & $12.2(1.7)$ \\
\hline Cardiac output (litre/min) & $4.0(0.2)$ & $3.7(0.2)$ \\
\hline
\end{tabular}

Values are mean (SEM). NYHA.

${ }^{\star} \mathrm{p}<0.05$ ( $v$ non-cachectic).

New York Heart Association functional class.

ischaemic heart disease patients (table 1). Plasma $\mathrm{TNF} \alpha$ was significantly higher in patients with cachectic heart failure than in non-cachectic heart failure $(p=0.006)$ or ischaemic heart disease $(p=0.04)$. The distribution of plasma TNF $\alpha$ concentrations in each group is shown in fig 2 .

PLASMA NORADRENALINE CONCENTRATIONS

The mean plasma noradrenaline concentration was $4.5(0.4) \mathrm{nmol} / 1$ in cachectic heart failure patients and $3.5(0.3)$ in non-cachectic heart failure patients. There was a trend for plasma noradrenaline to be higher in the cachectic heart failure than in non-cachectic heart failure $(p=0.09 ;$ table 1$)$.

PLASMA LEPTIN AND HAEMODYNAMIC MEASUREMENTS

In patients with cachectic chronic heart failure there was a non-significant trend towards a greater severity of haemodynamic disturbance than in non-cachectic heart failure patients (table 2). However, no significant correlation between plasma leptin concentration and left ventricular ejection fraction or any of the other haemodynamic variables was observed (NS by analysis of covariance).

\section{PLASMA LEPTIN AND NYHA CLASS}

The NYHA class of patients with cachectic chronic heart failure was significantly higher than in patients with non-cachectic chronic heart failure, at 2.7 (0.11) v 2.4 (0.12), $\mathrm{p}<0.05$. The correlation between NYHA class and plasma leptin concentration was, however, poor $(r=0.15, \mathrm{p}=0.20)$. 


\section{Discussion}

We have shown that patients with cachectic chronic heart failure have significantly lower plasma leptin concentrations than patients with non-cachectic chronic heart failure or with ischaemic heart disease but normal left ventricular function. A rise in plasma leptin concentration relative to body fat content does not therefore seem to be an aetiological factor in the cachexia associated with chronic heart failure, assuming normal central transport of leptin and normal leptin receptor sensitivity. In other words, the leptin negative feedback loop appears to be functioning effectively, or even in an exaggerated fashion, in cachectic chronic heart failure patients. Indeed, plasma leptin concentrations in cachectic patients with chronic heart failure are inappropriately low (fig 1).

Our findings are to some extent surprising and give new insights into the physiology of leptin control. For example, TNF $\alpha$ concentrations-previously linked to cachexia in various conditions - are increased in chronic heart failure. ${ }^{7-9} \mathrm{TNF} \alpha$ has been shown to increase circulating leptin concentrations in several species, including humans. ${ }^{10-12}$ Furthermore, other mediators known to increase leptin, such as insulin, growth hormone, and cortisol, are themselves increased in chronic heart failure. ${ }^{18-20}$ Also, as leptin is cleared from the circulation by the kidneys, ${ }^{21}{ }^{22}$ and chronic heart failure is associated with renal dysfunction, plasma concentrations might be expected to be increased, as they are in renal failure. ${ }^{23}$ Despite this, plasma leptin concentrations appear not just low but inappropriately low in cachectic chronic heart failure.

Why then might leptin concentrations be reduced in cardiac cachexia in the face of all these influences to the contrary? It has been suggested that cachexia is associated with more deranged cardiac haemodynamics, but this did not explain the difference in leptin concentrations in our cachectic patients. Decreased food intake and increased energy expenditure are known to decrease leptin secretion. The former has never been clearly or consistently implicated in cardiac cachexia. ${ }^{9425}$ Recently, however, enhanced energy expenditure has been described in chronic heart failure, ${ }^{2627}$ and could play a partial role in cachexia and, perhaps, in leptin suppression. Another possible, and potentially related, explanation is the sympathetic nervous system overactivity that characterises chronic heart failure. $\beta_{3}$ Adrenoceptor activation by noradrenaline, for example, decreases leptin release experimentally both in vivo and in vitro. ${ }^{28-30}$ Acute adrenergic stimulation has also been reported to decrease plasma leptin concentration. ${ }^{31}$ Recently, isoprenaline infusion has been shown to reduce plasma leptin concentration in humans. ${ }^{32}$ Our cachectic patients tended to have higher plasma noradrenaline concentrations in keeping with this view, and recently another group has shown that patients with cardiac cachexia have much higher noradrenaline concentrations than non-cachectic patients with chronic heart failure. ${ }^{20}$ More sophisticated and accurate methods of measuring sympathetic nerv- ous system activity would, however, be needed to test this hypothesis properly.

Interestingly, the administration of leptin to leptin deficient mice increases their activity as well as decreasing their food intake. ${ }^{33}$ It is possible, therefore, that the low plasma leptin concentrations in cachectic chronic heart failure may contribute to the symptoms of fatigue and lethargy which are common in this syndrome. This could also explain the more severe functional limitation observed in cachectic chronic heart failure patients and the higher NYHA class observed in our study.

\section{CONCLUSIONS}

In summary, this study shows that the cachexia associated with heart failure is not caused by enhanced leptin release, despite the activation of multiple leptin stimulating pathways in this syndrome. In other words, powerful leptin suppressing mechanisms appear to be operating in chronic heart failure and opposing the effect of factors such as TNF $\alpha$, insulin, corticosteroids, and growth hormone. One possible explanation for both the low leptin concentrations and increased metabolic rate in cachectic chronic heart failure is activation of the sympathetic nervous system.

The Medical Research Council supports DRM, ER, HJD, JJM, and JJVMcM. This study was presented in part at the 70th Scientific Sessions of the American Heart Association, Orlando, European Society of Cardiology, Vienna, August 1998.

1 Zhang YY, Proenca R, Maffei M, et al. Positional cloning of the mouse obese gene and its human homolog. Nature 1994;372:425-32.

2 Considine RV, Sinha MK, Heiman ML, et al. Serum immunoreactive leptin concentrations in normal-weight and obese humans. N Engl F Med 1996;334:292-5.

3 Banks WA, Kastin AJ, Huang WT, et al. Leptin enters the brain by a saturable system independent of insulin. Peptides 1996;17:305-11.

4 Maffei M, Stoffel M, Barone M, et al. Absence of mutations in the human OB gene in obese/diabetic subjects. Diabetes 1996;45:679-82.

5 Considine RV, Considine EL, Williams CJ, et al. Evidence against either a premature stop codon or the absence of obese gene messenger-RNA in human obesity. F Clin Invest obese gene messenge

6 Maffei M, Halaas J, Ravussin E, et al. Leptin levels in human and rodent-measurement of plasma leptin and ob RNA in obese and weight-reduced subjects. Nat Med 1995;1:115561

7 McMurray JJV, Abdullah I, Dargie HJ, et al. Increased concentrations of tumour necrosis factor in "cachectic" patients with severe chronic heart failure. Br Heart $\mathcal{F} 1991$; 66:356-8

8 Levine B, Kalman J, Mayer L, et al. Elevated circulating levels of tumor necrosis factor in severe chronic heart failure. N Engl F Med 1990;323:236-41.

9 Zhao SP, Zeng LH. Elevated plasma levels of tumor necrosis factor in chronic heart failure with cachexia. Int $\mathcal{F}$
Cardiol 1997;58:257-61.

10 Sarraf P, Frederich RC, Turner EM, et al. Multiple cytokines and acute inflammation raise mouse leptin levels:
potential role in inflammatory anorexia. f Exp Med 1997;185: 171-5.

11 Grunfeld C, Zhao C, Fuller J, et al. Endotoxin and cytokines induce expression of leptin, the ob gene product, in hamsters-A role for leptin in the anorexia of infection. $\mathcal{F}$ Clin Invest. 1996;97:2152-7.

12 Zumbach MS, Boehme MWJ, Wahl P, et al. Tumor necrosis factor increases serum leptin levels in humans. $\mathcal{F}$ Clin Endocrinol Metab 1997;82:4080-2.

13 Simons JPFHA, Schols AMWJ, Campfield LA, et al. Plasma concentration of total leptin and human lung-cancerassociated cachexia. Clin Sci 1997;93:273-7.

14 Durnin JV, Rahaman MM. The assessment of the amount of fat in the human body from measurements of skinfold thickness. Br f Nutr 1967;21:681-9.

15 Durnin JV, Womersley J. Body fat assessed from total body density and its estimation from skinfold thickness: measurements on 481 men and women aged from 16 to 72 urements on 481 men and wome

16 Goldstein DS, Feuerstein G, Izzo JL, et al. Validity and reliability of liquid-chromatography with electrochemical detection for measuring plasma levels of norepinephrine and epinephrine in man. Life Sci 1981;28:467-75. 
17 Wallenstein S, Zucker CL, Fleiss JL. Some statistical methods useful in circulation research. Circ Res 1980;47:1-9.

18 Ads useful in circulation research. Circ Res 1980;47:1-9. gin. Studies of body water and sodium, renal function, hemodynamic indexes, and plasma hormones in untreated congestive cardiac failure. Circulation 1989;80:299-305.

19 Swan JW, Walton C, Godsland IF, et al. Insulin resistance in chronic heart failure. Eur Heart $\mathcal{f}$ 1994;15:1528-32.

20 Anker SD, Chua TP, Ponikowski P, et al. Hormonal change and catabolic/anabolic imbalance in chronic heart failure and their importance for cardiac cachexia. Circulation 1997;96:526-34

21 Cumin F, Baum HP, Levens N. Leptin is cleared from the circulation primarily by the kidney. Int f Obes Relat Metab Disord 1996;20:1120-6.

22 Esler M, Vaz M, Collier G, et al. Leptin in human plasma is derived in part from the brain, and cleared by the kidneys. derived in part from
Lancet 1998;351:879.

23 Iida M, Murakami T, Yamada M, et al. Hyperleptinemia in chronic renal failure. Horm Metab Res 1996;28:724-7.

24 Ansari A. Syndromes of cardiac cachexia and the cachectic heart: current perspective. Prog Cardiovasc Dis 1987;30:4560.

25 Morrison WL, Edwards RHT. Cardiac cachexia. BMf 1991;302:301-2.

26 Riley M, Elborn JS, McKane WR, et al. Resting energy expenditure in chronic cardiac failure. Clin Sci 1991;80 633-9.
27 Poehlman ET, Scheffers J, Gottlieb SS, et al. Increased resting metabolic rate in patients with congestive heart failure. Ann Intern Med 1994;121:860-2.

28 Trayhurn P, Duncan JS, Rayner DV, et al. Rapid inhibition of ob gene expression and circulating leptin levels in lean mice by the beta 3-adrenoceptor agonists BRL 35135A and ZD2079. Biochem Biophys Res Commun 1996;228:605-10.

29 Gettys TW, Harkness PJ, Watson PM. The beta 3-adrenergic receptor inhibits insulin-stimulated leptin secretion from isolated rat adipocytes. Endocrinology 1996; 137:4054-7.

30 Kosaki A, Yamada K, Kuzuya H. Reduced expression of the leptin gene (ob) by catecholamine through a G(s) proteincoupled pathway in 3T3-L1 adipocytes. Diabetes 1996;45: 1744-9.

31 Trayhurn P, Duncan JS, Rayner DV. Acute cold-induced suppression of ob (obese) gene expression in white adipose tissue of mice: mediation by the sympathetic system. Biochem f 1995;311:729-33.

32 Donahoo WT, Jensen DR, Yost TJ, et al. Isoproterenol and somatostatin decrease plasma leptin in humans: a novel mechanism regulating leptin secretion. 7 Clin Endocrinol Metab 1997;82:4139-43.

33 Pelleymounter MA, Cullen MJ, Baker MB, et al. Effects of the obese gene-product on body-weight regulation in $o b / o b$ mice. Science 1995;269:540-3. 